\title{
DESCRIÇÃO DE UMA NOVA ESPÉCIE DO GÊNERO PSEUDIONE KOSSMANN, 1881 (ISOPODA, BOPYRIDAE) ENCONTRADA PARASITANDO MUNIDA MICROPHTHALMA A. MILNE-EDWARDS, 1880 NO ATLÂNTICO SUDOESTE
}

\author{
Brito, $\mathrm{A}^{1, *} ;$ Cardoso, I. ${ }^{2} \&$ Boyko, C. ${ }^{3}$ \\ 1,2 Museu Nacional/Universidade Federal do Rio de Janeiro, Departamento de Invertebrados, Laboratório de

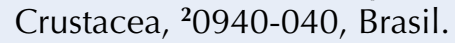 \\ ${ }^{3}$ Division of Invertebrate Zoology, American Museum of Natural History, Central Park West at 79th St., New York, \\ NY ${ }^{1} 00^{2} 4$, U.S.A. \\ ${ }^{3}$ Department of Biology, Hofstra University, Hempstead, New York ${ }^{11549,}$ U.S.A. \\ *Autor correspondente: ayrtonbrito@gmail.com
}

Bopyridae Rafinesque, 1815 é uma família de isópodes parasitas que vivem em cavidades branquiais de Decapoda. O grupo é dividido em dez subfamílias, incluindo Pseudioninae Codreanu, 1967 que tem como gênero tipo Pseudione Kossmann, 1881. Um total de 21 espécies de Bopyridae são conhecidas para a costa brasileira, mas até o momento apenas Paragigantione americana (Markham, 1974) havia sido registrada parasitando Munida microphthalma A. Milne-Edwards, 1880. Os espécimes de M. microphthalma aqui analisados foram coletados utilizando-se redes de pesca de arrasto durante os projetos OCEANPROF (Projeto Ambiental de Mar Profundo da Bacia de Campos) (1074-1649m) e HABITATS (Heterogeneidade Ambiental da Bacia de Campos) (45,9-2030m). Os Bopyridae encontrados neste material foram identificados com auxílio de vasta literatura. O material encontra-se depositado na coleção de Crustacea do Museu Nacional/UFRJ (MNRJ). Foi descrita uma nova espécie de Pseudione denominada Pseudione serejoae n. sp., a qual as fêmeas se assemelham com $P$. fibriata Richardson, 1910 e P. minimocrenulata Nierstrasz \& Brender à Brandis, 1931 devido a lâmina frontal crenulada e placas coxais com projeções pontiagudas irregulares, mas se diferencia das mesmas pelo aspecto "pinçado" da lamina basal, pereonitos com o meio estreito e margem posterior convexa, pereonitos 5-7 com margem laterais relativamente lisas e projeções da bárbula relativamente lisas com poucos lóbulos. Vinte um espécimes de $M$. microphthalma estavam parasitados pela espécie $P$. serejoae n. sp. O espécime que continha o holótipo e alótipo apresentavam fêmeas adultas parasitando ambos os lados da cavidade branquial. A série de amostras de P. serejoae n. sp. inclui fêmeas e machos adultos, machos subadultos e larvas criptoniscas. Está é uma série numerosa, revelando diferentes estágios da ontogenia, o que é incomum em Bopyridae.

Palavra-chave: Isopoda, Bopyridae, parasita, Pseudione, Munida. 